ASCLEPIO. Revista de Historia de la Medicina y de la Ciencia

65 (2), julio-diciembre 2013, p013

ISSN-L:0210-4466

http://dx.doi.org/10.3989/asclepio.2013.15

\title{
EL APÓCRIFO, PROTOTIPO DE UNA SUBJETIVIDAD EN CRISIS
}

\author{
Joan Oleza \\ Universitat de València \\ joan.oleza@uv.es
}

Recibido: 2 septiembre 2012; Aceptado: 17 marzo 2013.

Cómo citar este artículo/Citation: Oleza, Joan (2013), “El apócrifo, prototipo de una subjetividad en crisis”, Asclepio 65 (2): p013. doi: http:// dx.doi.org/10.3989/asclepio.2013.15

RESUMEN: En su introducción este trabajo pasa revista a la concepción del Sujeto que, con origen en la Antigüedad Clásica, se desarrolla en la cultura occidental hasta llegar a la llustración y el Romanticismo, añadiendo nuevos aspectos pero sin poner en cuestión su fundamento en un Sujeto substancial. La primera gran puesta en crisis de este fundamento, y de la herencia recibida, se manifiesta en el primer cuarto del siglo XX, tras la lectura y asimilación de la obra de Marx, de Freud o de Nietzsche, que sientan las bases para la crítica del Sujeto. Una manifestación de primer orden de la crisis que se deriva es la proliferación de la escritura apócrifa, que alcanza modelos alternativos en la obra de Fernando Pessoa y en la de Antonio Machado. Entre ambas se extiende el horizonte de referencia de la intensa y extensa colección de apócrifos de Max Aub. Este trabajo explora la significación de sus apócrifos fundamentales: Luis Álvarez Petreña y Jusep Torres Campalans, y frente a ellos el caso limítrofe de Luis Buñuel, tratado por Max Aub como un apócrifo de signo contrario.

PALABRAS CLAVE: Sujeto; crisis del Sujeto; Apócrifo; Pessoa; Machado; Max Aub; Luis Álvarez Petreña; Jusep Torres Campalans; Luis Buñuel.

\section{THE APOCRYPHAL: PROTOTYPE OF A SUBJECTIVITY IN CRISIS}

ABSTRACT: The introduction of this paper reviews the concept of the subject, which originated in classical antiquity and developed in Western culture up to the Enlightenment and Romanticism with the addition of new aspects but without questioning its foundation as a substantial Subject. The first major crisis of this received view took place in the first quarter of the twentieth century after the assimilation of the works by Marx, Freud or Nietzsche, which laid the foundations of a thorough criticism on the subject. One important feature of this crisis was the proliferation of apocryphal writing, which reached new models in the works of Fernando Pessoa and Antonio Machado. Between them lies the scope of the intensive and extensive collection of Max Aub's apocryphal writings. This paper explores the significance of his main apocryphal characters Luis Álvarez Torres Petreña and Jusep Torres Campalans, as well as of the borderline case of Luis Buñuel, which was handled by Max Aub as an apocryphal of opposite sign.

KEY WORDS: Subject; Crisis of the subject; Apocryphal; Pessoa; Machado; Max Aub; Luis Álvarez Petreña; Jusep Torres Campalans; Luis Buñuel.

Copyright: (c) 2013 CSIC. Este es un artículo de acceso abierto distribuido bajo los términos de la licencia Creative Commons Attribution-Non Commercial (by-nc) Spain 3.0. 


\section{LA MODERNIDAD Y LA HERENCIA DE LA SUBJETIVI- DAD CLÁSICA}

Los orígenes de la Modernidad reciben como herencia del mundo clásico la confianza en un sujeto substancial. Recuérdese la célebre definición de persona del Liber de persona et duobus naturis de Boecio: "La persona es una substancia individual de naturaleza racional". Santo Tomás, y con él toda la escolástica cristiana medieval, le añadió un aspecto nuevo, no menos fundamental, el de su capacidad de autodeterminación: la persona es aquel tipo especial de substancia individual que es una substancia racional - hasta aquí Boecio-, que posee el dominio de sus propios actos, y la facultad de actuar por sí misma (Ferrater Mora, 1965, p. 403). Pico della Mirandola y la filosofía del primer Renacimiento, sin modificar esta concepción, acentuaron la capacidad del hombre de hacerse a sí mismo, como un "ser camaleónico», "de naturaleza multiforme y mudadiza», y ampliaron su territorio, le otorgaron un escenario a la vez central y dilatado, en el que podía desplegar toda su potencialidad:

Así pues, [el supremo Artesano] hizo del hombre la hechura de una forma indefinida, $y$, colocado en el centro del mundo, le habló de esta manera: [...] $\mathrm{Ni}$ celeste ni terrestre te hicimos, ni mortal ni inmortal, para que tú mismo, como modelador y escultor de ti mismo, más a tu gusto y honra, te forjes la forma que prefieras para ti. Podrás degenerar a lo inferior, con los brutos; podrás realzarte a la par de las cosas divinas, por tu misma decisión (Mirandola, 1984, p. 105).

En el siglo siguiente, y en el trayecto que media entre la época del Renacimiento europeo y la del Barroco, esta concepción del sujeto recibe una doble dirección de despliegue que conduce hasta el principio mismo de la Modernidad: con Montaigne el sujeto aparece asociado a la experiencia individual, con Descartes a la razón universal.

Esta apenas introducción debería servirme para calibrar la herencia de la que he hablado al principio: la de un sujeto de identidad individual y, por consiguiente, indivisible e irrepetible, que es además de naturaleza racional, y que situado en el centro de la naturaleza puede decidir su destino en el espacio dilatado pero también limitado de lo inmanente ${ }^{1}$. Este sujeto es substancial y no dependiente de sus accidentes. Como escuchamos proclamar orgullosamente a los personajes del teatro clásico español, "Yo soy yo" (Anteo en El caballero bobo, de Guillén de Castro), o "Yo soy el que soy" (Tragedia de los siete infantes de Lara, de Juan de la Cueva), o "Yo soy quien soy», como repiten una y otra vez los personajes de Lope y, sobre todo, de Calderón (vgr. El médico de su honra, o A secreto agravio, secreta venganza, entre las más conocidas), con una seguridad y una firmeza que convirtió la frase en un lugar común de los corrales de comedias.
Esta herencia será notablemente enriquecida ya a finales del XVIII por la obra de Rousseau, uno de los fundadores de la escritura del "yo" y el creador del género literario que le proporcionó un más preciso cauce, la autobiografía. Como será enriquecida por el Romanticismo, que crea en buena medida las bases de la sensibilidad moderna, o por el Realismo y el Decadentismo-Modernismo, que incorporan prototipos fundamentales de la subjetividad moderna. Pero este enriquecimiento del campo de la subjetividad y esta constante renovación de los prototipos de sujeto no ponen en cuestión la idea misma de sujeto que procede de la herencia clásica, aunque a veces, y en determinados momentos, se perciba la sombra de una amenaza incipiente, como en el caso del doble romántico, o ya acuciante, en el del héroe decadentista del Fin de Siglo. A fin de cuentas, y como enuncia Habermas (1987), la Modernidad encuentra uno de sus principios determinantes en la Razón centrada por el Sujeto.

La primera gran puesta en crisis de esa idea, y de la herencia recibida, se manifiesta a mi modo de ver en el primer cuarto del siglo $\mathrm{XX}$, y encuentra una manifestación de primer orden en la proliferación de la escritura apócrifa. A ella quiero dedicar, como expresión de una fase determinada de la historia de la subjetividad moderna, las líneas que siguen.

\section{EL LADO APÓCRIFO DE LA MODERNIDAD}

Aunque la Modernidad se sustenta sobre valores como la originalidad y la autenticidad, conoce también toda una contrapartida de falsificaciones y suplantaciones que vienen a constituir su lado apócrifo, una especie de continente sumergido y, en buena medida, represaliado, en el que se entremezclan falsificaciones literarias (Macpherson, Adolfo de Castro, Romain Gary, etc.) y artísticas (Hans Van Meegeren, Elmyr de Hory, etc.), con otras, las más, que son expresión de patologías psíquicas o, bien al contrario, estrategias conscientes para poner a prueba principios literarios tan arraigados como la frontera entre realidad y ficción, o entre historia y novela, o valores como el de autoridad textual. Si bien los antecedentes son múltiples ${ }^{2}$, el punto de referencia inicial, en la literatura europea moderna, hay que situarlo en 1760, cuando un joven escocés, de nombre James Macpherson, dotado de ciertos conocimientos de la poesía gaélica antigua que todavía se difundía oralmente en su natal Invernesshire, publicó unos Fragments of Ancient Poetry Collected in the Highlands of Scotland, and Translated from the Gallic or Erse Language. Era el primer aldabonazo. Después aparecieron dos poemas épicos Fingal (1761) y Temora (1763), obra de un legendario guerrero y bardo gaélico, Ilamado Ossian, que se suponía haber vivido nada menos que en el siglo III antes de Cristo. Cinco años más tarde se publi- 
caban los dos volúmenes de The Works of Ossian. En Europa fueron toda una revelación, y también la señal auroral que una época ya preñada de romanticismo estaba esperando. Goethe hizo que Werther y Carlota llorasen con las baladas de Ossian.

El caso de Ossian se extendió por Europa, y España no fue una excepción. Ya en 1787, el padre Isla, al adaptar al castellano la novela francesa Gil Blas de Santillana, acusaba a su autor Monsieur Le Sage de falsificación, por haber usurpado un manuscrito en español convirtiéndolo en novela propia en francés, y lo remediaba sacándose de la pluma las Aventuras de Gil Blas de Santillana, robadas a España, adoptadas en Francia por Monsieur le Sage, restituidas a su Patria y a su Lengua nativa, por un español zeloso que no sufre que se burlen de su nación. Por su parte, hacia 1800, José Marchena, editaba un fragmento perdido del Satiricón de Petronio (Fragmentum Petronii), descubierto según él en un códice del monasterio de Saint Gall, y Leandro Fernández de Moratín, hacia 1815, trabajaba en crear un Guzmán de Alfarache suyo, acorde con los gustos del XVIII y que pretendía hacer pasar por una versión de la novela realizada por el propio Mateo Alemán y hasta entonces desconocida (Álvarez Barrientos, 2009, pp. 822-825); por su parte, el erudito Adolfo de Castro escribía a nombre de Cervantes una Epístola a Mateo Vázquez o un opúsculo inédito, El Buscapié (1848), supuestamente escrito por Miguel de Cervantes en defensa de la primera parte del Quijote. En Francia, Prosper Merimée, veinte años antes de Carmen, se sacaba de la faltriquera a toda una dramaturga española del siglo XVII, Clara Gazul, de sangre morisca «et arrière petite fille du tendre Maure Gazul, si fameux dans les vieilles romances espagnoles», cuyas obras publicaba en francés bajo el título de Théâtre de Clara Gazul (1825), precedidas de un retrato de la dramaturga por Étienne-Jean Delécluze.

Pero, a finales del siglo XIX y principios del XX, la invención de un apócrifo (es el concepto que utiliza Machado) o heterónimo (el que utiliza Pessoa) se convierte en juego literario y proliferan artistas-escritores imaginarios que se presentan, en buena medida, como máscaras, como alter ego o doble de su autor, sin que el verdadero autor ponga demasiada insistencia en su existencia real e independiente: es el Adoré Floupette con quien Henri Beauclair y Gabriel Vicaire parodiaron a los decadentistas, el Monsieur Teste de Paul Valéry, el Malte Laurids Brigge de Rainer María von Rilke, el A.O. Barnabooth de Valéry Larbaud, el André Walter de André Gide, el supuesto poeta desconocido, Rafael, de las rimas de Teresa de Unamuno, el Azorín de José Martínez Ruiz, el Sigüenza de Gabriel Miró, el Octavi de Romeu de Eugeni d'Ors, etc. Especímenes de un cambio profundo en el desempeño de la subjetividad moderna, todas estas máscaras son más bien personajes literarios que mantienen una relación de dependencia tan ambigua como sutilmente variada con sus autores, a veces, incluso, de interdependencia, como en el caso de Azorín, en el que el personaje creado en 1902 acaba superponiéndose al autor, José Martínez Ruiz, nacido en 1873, y engulléndose su nombre para poder encarnar su figura. Ninguno de ellos, quizás con la excepción del poeta y riche amateur, Archibald Olson Barnabooth, tiene no obstante voluntad expresa de independencia de su autor. Para llegar al apócrifo emancipado y con obra propia hay que llegar a Antonio Machado y a Fernando Pessoa, dos de los arcángeles mensajeros de Luis Álvarez Petreña y Jusep Torres Campalans. Uno y otro nos ofrecen aspectos fascinantes, aunque alternativos, como he estudiado en otro lugar (Oleza, 2003), de la condición de apócrifo.

En el caso de Pessoa nos encontramos con el escritor occidental contemporáneo que más radicalmente experimenta el estallido del yo substancial, racional e individual que nos había legado el Renacimiento. La experiencia personal que se traduce en su obra oscila desde la negación de sí mismo a la afirmación de una pluralizada otredad ( Sou variamente outro do que um eu que não sei se existe»), desde el sentimiento de mutilación («Soy un fragmento de mí conservado en un museo abandonado» (Pessoa, 1984, p. 9)), hasta la disgregación en múltiples yos («Sinto-me múltiplo. Sou como um quarto com inúmeros espelhos fantásticos que torcem para reflexões falsas uma única anterior realidade que não está em nenhuma e está em todas» (citado por Carreño, 1981, p. 104), pasando una y otra vez por esos momentos agudos de percepción de lo que él llamó "estado actual de no-ser» (Pessoa, 1984, p. 9).

Un estallido tan radical de la subjetividad solo podría traducirse en una escritura diseminada, escindida en fragmentos, dispersa en modalidades, géneros, posiciones textuales, puntos de vista, autores diversos, heterónimos en suma. La aprehensión del mundo pierde su perspectiva, y con ella su orden jerárquico y unitario. Hay un texto impresionante, titulado "Aspectos", que como la mayoría de los suyos, permaneció manuscrito y amontonado en un baúl hasta después de su muerte, y que ofrezco en traducción de Ángel Crespo, en el que Pessoa explica lo inevitable de sus heterónimos:

A cada personalidad más dilatada que el autor de estos libros ha conseguido vivir dentro de sí, le ha concedido una índole expresiva, y ha hecho de esa personalidad un autor con un libro, o libros, con las ideas, las emociones, y el arte de los cuales él, el autor real (o por ventura aparente, porque no sabemos lo que es la realidad), nada tiene [que ver], salvo el haber sido, al escribirlas, el médium de unas figuras que él mismo ha creado. [...] El autor humano de estos libros no conoce en sí mismo personalidad ninguna. Cuan- 
do acaso siente una personalidad emerger dentro de sí, pronto ve que es un ente diferente del que él es, aunque parecido; hijo mental, quizás, y con cualidades heredadas, pero (con) las diferencias de ser otro (Pessoa, 1984, p. 10).

El período de incubación de los heterónimos, al menos de los tres principales, Alberto Caeiro, Álvaro de Campos y Ricardo Reis, es el que se extiende entre 1912 y 1914, pero alrededor de ellos brotó toda una caterva de heterónimos menores, haciendo aflorar ese drama em gente, esa representación dramática dividida en personajes y no en actos o jornadas, esa ficción multipolar que dio nacimiento a toda una consigna: fingir é conhecer-se.

Los primeros apócrifos de Machado saltaron a la luz tardíamente, pues permanecían inéditos en un cuaderno de Apuntes que Guillermo de Torre rebautizó como Los complementarios al publicarlo parcialmente en 1957. En este cuaderno, y bajo el título de Cancionero apócrifo, aparecía una curiosa antología de Doce poetas que pudieron existir - aunque en realidad eran catorce-, compuesta hacia 1923, diez años largos después del nacimiento de los heterónimos de Pessoa. Se trata de poetas supuestamente nacidos a lo largo de todo el siglo XIX, desde 1812 hasta 1899, por lo que alguno de ellos no estaba muerto todavía en el momento de ser inventado. Posiblemente el más singular de los catorce es el que lleva el número 5 . Su escueta nota biográfica dice: "Antonio Machado. Nació en Sevilla en 1895. Fue profesor en Soria, Baeza, Segovia y Teruel. Murió en Huesca en fecha no precisada. Algunos lo han confundido con el célebre poeta del mismo nombre, autor de Soledades, Campos de Castilla, etcétera». Poco después, en la Revista de Occidente (1926) y en la segunda edición de sus Poesías Completas (1928), Machado publicó sendos textos correspondientes a dos nuevos apócrifos: el primero era un poeta y filósofo del siglo XIX llamado Abel Martín, y el segundo un discípulo suyo, Juan de Mairena, un guasón «poeta, filósofo, retórico e inventor de una máquina de cantar». El último es embrión de una progenie de textos que no cesará de crecer hasta la muerte del poeta, una parte de los cuales agrupó en el libro Juan de Mairena. Sentencias, donaires, apuntes y recuerdos de un profesor apócrifo (1936).

Los personajes apócrifos de Machado van surgiendo a medida que va creciendo su discrepancia con los jóvenes poetas del 27, fascinados por Juan Ramón, por el conceptismo gongorino y por los juegos de las primeras vanguardias deshumanizadas. Machado se lo explica a Ernesto Jiménez Caballero en un texto fundamental:

Entre manos tengo mi tercer poeta apócrifo: Pedro de Zúñiga, poeta actual nacido en 1900 . Acaso encuentre en la ideología de este poeta motivos de simpatía. Abel Martín y Juan de Mairena son dos poetas del siglo XIX que no existieron, pero que debieron existir, y hubieran existido si la lírica española hubiera vivido su tiempo. Como nuestra misión es hacer posible el surgimiento de un nuevo poeta, hemos de crearle una tradición de donde arranque y él pueda continuar. Además, esa nueva objetividad a que hoy se endereza el arte, y que yo persigo hace veinte años, no puede consistir en la lírica - ahora lo veo muy claro- sino en la creación de nuevos poetas - no nuevas poesías-, que canten por sí mismos (Machado, 1928a, p. 1).

Afloran así, nítidamente, los fundamentos de los apócrifos machadianos: se trata de crear a lo largo del siglo XIX una tradición de poetas que no existió en España, que sea capaz de engendrar a los nuevos poetas que todavía no existen, pero que deberían comparecer para encarnar una poesía basada en una «nueva objetividad», alternativa a la de los jóvenes vanguardistas y neogongorinos. Tres años más tarde de esta carta, Machado ha profundizado sus ideas y envía a Gerardo Diego un "Arte poética» que acompañe sus poemas en la célebre antología de 1931, Poesía española contemporánea, con la que el grupo de poetas del 27 trataba de establecer su canon poético del siglo $X X$. La humorada inicial, la de Los complementarios, en pocos años adquiere así una fascinante tarea estratégica: se trata ahora de desafiar a la poesía española (e incluso a la occidental), a la que responsabiliza de haber conducido al callejón sin salida de una poesía deshumanizada, autoexcluida del tiempo y de la historia, ensimismada y solipsista. A la altura de 1930, el cincuentón Machado reta a un combate de antologías a la infame turba de poetas contemporáneos, y convoca en su apoyo a una hueste de poetas y filósofos fantasmales. Ninguno tan radical en sus planteamientos como Jorge Meneses, apócrifo del apócrifo Juan de Mairena, un apócrifo al cuadrado, a quien escuchamos en diálogo con su maestro e inventor:

Meneses - Pronto el poeta no tendrá más recurso que enfundar su lira y dedicarse a otra cosa.

Mairena —¿Piensa usted?...

Meneses - Me refiero al poeta lírico. El sentimiento individual, mejor diré: el polo individual del sentimiento, que está en el corazón de cada hombre, empieza a no interesar, y cada día interesará menos. La lírica moderna, desde el declive romántico hasta nuestros días (los del simbolismo), es acaso un lujo, un tanto abusivo, del hombre manchesteriano, del individualismo burgués, basado en la propiedad privada. El poeta exhibe su corazón con la jactancia del burgués enriquecido que ostenta sus palacios, sus coches, sus caballos, y sus queridas. El corazón del poeta, tan rico en sonoridades, es casi un insulto a la afonía cordial de la masa, esclavizada por el trabajo mecánico. La poesía lírica se engendra siempre en la zona central de nuestra psique, que es la del sentimiento; no hay lírica que no sea sentimental. Pero el sentimiento ha de tener tanto de individual como de genérico, porque aunque no existe un corazón en ge- 
neral, que sienta por todos, sino que cada hombre lleva el suyo y siente con él, todo sentimiento se orienta hacia valores universales, o que pretenden serlo. Cuando el sentimiento acorta su radio y no trasciende del yo aislado, acotado, vedado al prójimo, acaba por empobrecerse, $y$, al fin, canta de falsete. Tal es el sentimiento burgués, que a mí me parece fracasado; tal es el fin de la sentimentalidad romántica. [...] Un corazón solitario - ha dicho no sé quién, acaso Pero Grullo- no es un corazón; porque nadie siente si no es capaz de sentir con otro, con otros... ¿ ¿por qué no con todos?

Mairena -iCon todos! iCuidado, Meneses!

Meneses -Sí, comprendo. Usted, como buen burgués, tiene la superstición de lo selecto, que es la más plebeya de todas. Es usted un cursi.

Mairena-Gracias.

Meneses - Le parece a usted que sentir con todos es convertirse en multitud, en masa anónima. Es precisamente lo contrario. Pero no divaguemos. Hay una crisis sentimental que afectará a la lírica, y cuyas causas son muy complejas. [...] Una nueva poesía supone una nueva sentimentalidad, y esta, a su vez, nuevos valores (Machado, 1928b, pp. 261-263).

\section{UN TRIPLE ASALTO A LA IDEA DE SUJETO}

La proliferación de toda una escritura apócrifa en el primer cuarto del siglo XX, supone un auténtico asalto a la idea de sujeto recibida de la herencia clásica y desarrollada por la Modernidad. Un asalto que se efectúa, a mi modo de ver, desde, al menos, tres vías principales: el vitalismo e irracionalismo nietzscheanos, de un lado, el marxismo, de otro, y el psicoanálisis de un tercero.

Sobre el marxismo apenas cabe insistir. Ya desde mediados del siglo XIX Marx desplazó el eje de la historia y de la filosofía desde el individuo a las formaciones y las clases sociales, a las fuerzas y a las relaciones de producción. Si el joven Marx está dominado todavía por el humanismo racionalista liberal, más cercano a Kant y a Fichte que a Hegel, su segunda etapa (1842-45) la elabora bajo la influencia de otra forma de humanismo, el humanismo "comunitario» de Feuerbach, pero a partir de 1845, como escribió L. Althusser (1965) en un ensayo célebre, Marx rompió radicalmente con toda teoría que fundara la historia y la política en una supuesta esencia universal del hombre, cuyo sujeto real fuera el individuo considerado aisladamente. Esta ruptura comportaba tres aspectos indisociables: la formación de una teoría de la historia y de la política fundada en conceptos innovadores; la crítica radical de las pretensiones teóricas de todo humanismo filosófico; y la consiguiente definición del humanismo como ideología. Fuese o no exacta históricamente y en toda su extensión la tesis de Althusser según la cual "el marxismo no es un humanismo», lo cierto es que de Marx a Althusser y de Lukács a Bajtín o Goldmann, esto es, a lo largo y lo ancho de la filosofía, la sociología y la estética de influencia marxista, el sujeto y el estilo individuales pasaron a ser concebidos en función de instancias sociológicas e ideológicas que los trascendían. El sujeto personal de la herencia clásica dejaba su lugar de privilegio a un nuevo sujeto determinado colectivamente.

La segunda de las vías, el irracionalismo nietzscheano, venía a culminar toda una tradición de pensamiento alternativo, que se engendró y desarrolló en la oposición - casi en la clandestinidad - a la gran filosofía burguesa y racionalista del siglo XIX, y cuyo antecedente más ilustre lo constituye la obra de Schopenhauer. Este sentó algunos de los presupuestos básicos de la crisis del sujeto. Lo hizo al privilegiar el conocimiento práctico, intuitivo, sobre el conocimiento de las representaciones, vinculadas a la actividad racional del sujeto; al concebir al individuo como la objetivación de la voluntad de vivir y sometido a sus impulsos; al establecer que la voluntad de vivir de cada individuo no es sino emanación de una voluntad universal, sin objeto ni fin alguno más allá de sí misma, empeño inexorable en que todos participamos, del que surgimos como efímeras anécdotas, al que regresamos despojados de nuestra individualidad. Schopenhauer inició esa gran negación del sentido que caracterizó a toda una manera de pensar la Modernidad, al deducir de la falta de finalidad de la voluntad, de su condición de esfuerzo ciego e infinito, la falta de sentido último de la vida, o al denunciar la carnicería que, en última instancia, parece el resultado más reiterado de la historia humana.

A finales de siglo, Nietzsche sustituyó la voluntad de vivir por la voluntad de poder, pero mantuvo la misma concepción de un sujeto cuya razón desconoce o enmascara los verdaderos impulsos que trabajan dentro de él y a veces contra él, y analizó la historia humana como la más violenta refutación práctica de los sistemas morales que practica en teoría: «El que conoce camina entre los hombres como entre animales», declara Zaratustra, «mas, para el que conoce, el hombre mismo se llama: el animal que tiene las mejillas rojas», y exclama: "Vergüenza, vergüenza, vergüenza - iesa es la historia del hombre!» (Nietzsche, 1975, p. 135). Pero el hombre de Nietzsche, el sujeto de esta historia de vergüenza, es un ser al que desde la niñez se le impone una educación opresora que acabará proporcionándole una moral de esclavo y convirtiéndolo en un lisiado, en un fragmento de hombre: «jEn verdad amigos míos, yo camino entre los hombres como entre fragmentos y miembros de hombres!», dice Zaratustra a sus discípulos (Nietzsche, 1975, p. 204).

La idea misma del hombre como sujeto de una razón con la que se regula a sí mismo y regula también la 
naturaleza resulta para Nietzsche una pura ficción: el conocimiento mismo está motivado por la voluntad de poder, expresa el deseo de dominar una cierta zona de la realidad para ponerla al servicio de esa voluntad. La voluntad de saber es en realidad voluntad de poder y el objetivo del conocimiento no es saber por saber sino saber para controlar. La realidad es un devenir, un fluir informe; somos nosotros quienes la transformamos en ser, imponiéndole normas, fórmulas, esquemas, orden, forma; y lo hacemos para poder dominarla, gobernarla, controlarla. Exactamente igual hacemos con nosotros mismos: el concepto del yo, del sí-mismo, es la ficción que imponemos a nuestro devenir, los límites con que lo encauzamos para poder enfrentarnos a la vida; a fin de cuentas los seres que no ven correctamente tienen ventajas respecto a los que ven que todo fluye; el hombre que mira en un solo sentido, y siempre hacia adelante, avanza más deprisa que aquel que dispersa, con curiosidad, su mirada.

La concepción que Nietzsche tiene del sujeto no se limita a la supeditación de su razón a su voluntad de poder, ni a su condición de lisiado por la educación y la cultura, ni a la fijación del devenir de su vida en una máscara social; también se expresa en la imagen del tránsito y del ocaso. "Oh hermanos míos - dice Zaratustra - lo que yo puedo amar en el hombre es que es un tránsito y un ocaso" (Nietzsche, 1975, p. 383). En su estado actual «el hombre es algo que debe ser superado» (Nietzsche, 1975, p. 81), superado en dirección al hombre superior, y desde este superado hasta alcanzar la condición de superhombre. Nietzsche propone por consiguiente un nuevo egocentrismo, una nueva subjetividad, la del superhombre, pero este solo podrá nacer de los escombros del sujeto lisiado y esclavo de la civilización occidental.

En cuanto al psicoanálisis, he aquí las palabras con las que Freud hacía balance en 1930 de sus efectos sobre la imagen idealista del yo:

En condiciones normales nada nos parece tan seguro y establecido como la sensación de nuestra mismidad, de nuestro propio yo. Este yo se nos presenta como algo independiente, unitario, bien demarcado frente a todo lo demás. Solo la investigación psicoanalítica [...] nos ha enseñado que esa apariencia es engañosa; que, por el contrario, el yo se continúa hacia adentro, sin límites precisos, con una entidad psíquica inconsciente que llamamos ello y a la cual viene a servir como de fachada. [Asimismo] la patología nos presenta un gran número de estados en los que se torna incierta la demarcación del yo frente al mundo exterior, o donde los límites llegan a ser confundidos [...] de modo que también el sentimiento yoico está sujeto a trastornos, y los límites del yo con el mundo exterior no son inmutables (Freud, 1970, pp. 9-10).

Por otra parte, el mismo "yo» es el producto de un proceso de diferenciación y atrofia: originalmente el yo lo incluye todo; luego, desprende de sí un mundo exterior. Nuestro actual sentido yoico no es, por consiguiente, más que el residuo atrofiado de un sentimiento más amplio [...] que correspondía a una comunión más íntima entre el yo y el mundo circundante (Freud, 1970, p. 11).

El sujeto fue analizado por el psicoanálisis a la manera de la estructura del átomo por la física, mucho más como un juego de atracciones y repulsiones, de instintos y de represiones, procedentes de fuentes individuales o transindividuales de signo contrapuesto que como un esquema unificado de personalidad. «El Ego, ese residuo del sujeto filosófico, es un débil mediador entre las demandas del $I d$ y las amenazas del Superego", a decir de Albrecht Wellmer (1988, p. 117), quien añade:

El sujeto descentrado del psicoanálisis es, en otras palabras, un punto de encuentro de fuerzas psíquicas y sociales más bien que señor de ellas, el escenario de una cadena de conflictos, más que el autor de un drama o el autor de una historia (Wellmer, 1988, p. 117).

La imagen del individuo emanada del psicoanálisis freudiano era una imagen polémica, de enfrentamiento permanente con ese "ello» que, a manera de continente sumergido y en estado de permanente actividad, procedía como un enemigo interno contra el que el propio sistema defensivo desplegaba toda una estrategia que Freud bautizó como «represión»: «Su esencia consiste exclusivamente - dice de ella - en rechazar y mantener alejados de lo consciente a determinados elementos", los impulsos instintivos (Freud, 1970 , p. 156). "Se trata del descubrimiento del otro de la razón dentro del sujeto y de su razón», escribe Wellmer, y añade: «el descubrimiento de Freud (o de Nietzsche) consistió en buena medida en que el deseo (o la voluntad de poder) estaba siempre presente como fuerza no racional dentro de la argumentación racional y de la convivencia moral» (Wellmer, 1988, pp. 117-118).

Nietzsche y Freud convergían en lo que Arnold Hauser caracterizó magistralmente como «psicología del desvelamiento». Tanto uno como otro parten de la tesis de que la vida manifiesta de la mente, esto es, lo que los hombres conocen y pretenden conocer sobre las razones de su conducta, es solamente el disfraz y la deformación de los verdaderos motivos de sus sentimientos y acciones. Para Nietzsche estos motivos se engendran en la voluntad de poder, para Freud en el inconsciente. Pero pensaran lo que quisieran Nietzsche y Freud de Marx, cuando ellos estaban desarrollando sus doctrinas seguían en sus desvelaciones la misma técnica de análisis que se había puesto en uso con el materialismo histórico. También Marx asegura que la conciencia de los hombres está desfigurada y corrompida, y que estos ven el mundo desde una perspectiva falsa, la de la ideología o "falsa concien- 
cia», determinada a su vez, y en última instancia, por su posición en las relaciones de producción.

El principio fundamental de la nueva técnica de análisis fue la sospecha de que detrás de todo el mundo manifiesto hay uno latente, detrás de todo lo consciente, un subconsciente, y detrás de todo lo unitario en apariencia, una contradicción. [...] Ellos descubrieron, cada uno a su modo, que la autodeterminación de la mente era una ficción y que nosotros somos esclavos de una fuerza que trabaja en nosotros y con frecuencia contra nosotros (Hauser, 1964, Vol. II, pp. 455-456).

\section{MAX AUB Y LA ESCRITURA APÓCRIFA}

Aunque la primera salida de un apócrifo maxaubiano data de 1932-1934, apenas cuatro años después de ver la luz Juan de Mairena, el período de máxima productividad de su escritura apócrifa es el que transcurre en plena madurez, durante los últimos 25 años de su vida: en 1958 publica Jusep Torres Campalans, en 1963 la Antología traducida, en 1964 el Juego de cartas, en 1965 la segunda versión de Luis Álvarez Petreña, en 1967 Imposible Sinaí, en 1970 la última versión de su Petreña, ahora titulada Vida y obra de Luis Álvarez Petreña, y durante los tres últimos años de su vida trabaja intensamente en una aventura todavía más audaz, la de tratar a un personaje real, bien conocido, y todavía en activo, como si fuera un apócrifo, en un texto que desgraciadamente quedó inacabado a su muerte, Luis Buñuel. Novela.

De los heterónimos de Pessoa, Max Aub heredó la radical alteridad, la neta diferenciación de los Alberto Caeiro, Ricardo Reis o Álvaro de Campos con respecto a su inventor, Fernando Pessoa. Y en efecto, tanto Campalans como Petreña son muy distintos, radicalmente distintos, diría sin dudarlo, de la imagen de sí mismo que Max Aub elabora en su obra; distintos en cuanto a la personalidad que les diseña, y con respecto a la cual mantiene toda una distancia, a menudo irónica, pero distintos también por la obra que les atribuye: los relatos de Petreña, todos con un cierto sello de autor, un cierto estilo reconocible, o los dibujos y pinturas de Campalans, que llegaron a tener catálogo y varias exposiciones propias, y también a situarse en el mercado; y distintos por último por la galaxia de amigos, relaciones, testimonios, pruebas documentales que envuelven a cada uno de ellos. Pero si de Pessoa hereda la alteridad de sus apócrifos, de Antonio Machado hereda la estrategia y los presupuestos ideológicos. Basta leer su ensayo Poesía española contemporánea para constatar que Max Aub conoció, probablemente desde su primera aparición en la Revista de Occidente y en las Poesías completas, a Abel Martín y Juan de Mairena, y en consecuencia a Jorge Meneses, y que se apercibió de inmediato de su importancia para la comprensión de la obra de Machado (Aub, 1969, p.
55). Conocería también, con bastante probabilidad, los artículos publicados en la prensa madrileña entre 1934 y 1936, que culminarían en el libro Juan de Mairena (1936), y los que continuaron publicándose durante la guerra civil, época en la que «nos vimos a menudo», según cuenta Max (Aub, 2001, p. 168), sobre todo en Rocafort, en la villa valenciana que el gobierno de la República había puesto a disposición del poeta y su familia, y en la que le confió lo mucho que le debía a Mairena (Aub, 2001, p. 169). En el Manual de literatura española (1966) se hace cargo, además, de la publicación póstuma de Los Complementarios (1957), la primera antología de apócrifos que concibió Machado y que, sin duda, influyó en su propia concepción de la Antología traducida (1963).

Y Max Aub no olvidó la lección. Usó a sus apócrifos para combatir la dirección dominante del arte contemporáneo, la que, arrancando del Romanticismo alemán, evolucionó hacia el Modernismo, la deshumanización del arte, la poesía pura y el arte abstracto. Pero los usó de manera distinta, invirtiendo el planteamiento. Los apócrifos de Machado son sus aliados, los de Max Aub sus antagonistas. En ellos identifica Aub las tendencias con las que pretende ajustar sus cuentas históricas. Jusep Torres Campalans es un hombre nacido en 1886 y forma parte, generacionalmente, de la promoción novecentista, la de Ortega, y tanto ideológica como estéticamente se nos presenta evolucionando desde el influjo noventayochista hacia los primeros movimientos vanguardistas, el cubismo muy especialmente, junto con Picasso; pero, a diferencia del pintor malagueño, Campalans se dirige progresivamente hacia la órbita de la deshumanización y de la pureza, con el decidido propósito de romper los vínculos con la tradición y de hacer brotar un arte nuevo, con un nuevo lenguaje, emancipado de la representación de la vida, que culminará en la pura abstracción. Al final de su trayectoria artística, las tramas geométricas de Mondrian desplazan al modelo de Picasso. El Gernika es rechazado. Después ya no queda más que el silencio.

La diferencia de posiciones con el Max Aub comprometido con un realismo de poderoso arraigo histórico y vinculación intensa a su época, que por esos mismos años escribe Campo del moro y Campo de los almendros, pero que ya antes ha escrito el Diario de Djelfa y los dramas mayores de su teatro, Morir por cerrar los ojos, San Juan o No, no puede ser más abismal. Max Aub ha buscado en Jusep Torres Campalans su diferencia, lo que le hace heterogéneo consigo mismo, el otro como antagonista. Y esa misma diferencia es la que le separa de su otro artista apócrifo, Luis Álvarez Petreña, once años más joven y representante de la generación siguiente, la de la dictadura, y muy distinto de Campalans como personaje. No obstante, ambos viven la misma experiencia histórico-cultural, la que 
transcurre entre el Modernismo, el Novecentismo y la Vanguardia; ambos comparten un individualismo excluyente; ambos asumen el arte como un universo al margen de la vida, exento de la contaminación social, que gira en torno a la indagación del lenguaje artístico y al alcance de la pureza; ambos, finalmente, son inevitablemente mediocres, el uno como escritor y el otro como pintor. Pero tal vez lo que más les identifica es su necesidad de huida, de escapar de sus vínculos, de sí mismos y hasta de su propio discurso. Los dos repiten el gesto de Rimbaud: incapaces de encontrar sentido a sus vidas dentro de la civilización en la que han crecido, renuncian, escapan de su medio pero también de sí mismos, de su obra, de todo lo que han sido. El uno finge un suicidio y termina al cabo de los años en un hospital de Londres, solo y con el nombre cambiado; el otro huye a la selva Lacandona, donde durante cuarenta años vive entre los indios chamulas, olvidado de cuanto fue, sin hacer nada que no sea estrictamente necesario para la subsistencia. En suma, tanto uno como otro le sirven a Max Aub para expresar la agonía del sujeto histórico modernista y el fracaso de una estética autosuficiente.

Luis Buñuel, en cambio, y a medida que Max Aub se introduce en su mundo, se va conformando como un personaje muy diferente a Campalans o a Petreña. Él representa lo que Víctor Fuentes, otro entusiasta de Buñuel, ha llamado «la otra cara del 27» (Fuentes, 1993), o si se prefiere, la otra cara de la Vanguardia. Buñuel se adhirió, como Campalans, a la Vanguardia, pero, a diferencia del pintor, su obra no evolucionó hacia la pureza y la abstracción, ni rompió los puentes entre experimentalismo y arraigo vital. En las páginas de su inacabada Luis Buñuel. Novela, Max se afana por comprender a Buñuel - cosa que no hizo ni con Petreña ni con Campalans- e identifica sus gustos propios con filmes que antes ha calificado de surrealistas: "Adoro La Vía Láctea - confiesa-, es una espléndida película» (Aub, 1985, p. 364). Es como si Max fuera comprendiendo que hay una conjugación posible de surrealismo y compromiso, de surrealismo y realismo, algo así como la síntesis del vanguardismo surrealista y la tradición galdosiana, tal como él lo puede comprobar en el cine que más le atrae de Buñuel: Tierra sin pan, Los olvidados, Nazarín, Viridiana, etc.

Probablemente esta hipotética simbiosis era la que él había buscado en libros como Jusep Torres Campalans y Luis Álvarez Petreña, tan atraídos por la representación realista de una época como por una factura vanguardista, libros-collage, pero también libros-superchería (con su pretensión de hacer pasar a sus protagonistas por personas reales), ejercicios de falsificación, que a lo que más se parecen es a las bromas surrealistas, esas bromas a las que Buñuel fue tan adicto durante toda su vida.

Por eso, probablemente, Max Aub no encontró dificultad en alternar, dentro de su producción, y en los mismos años, las novelas programáticamente realistas y formalmente vanguardistas de El laberinto mágico con las de ese vanguardismo realista que comienza a configurarse en Luis Álvarez Petreña y llega a su culminación en Jusep Torres Campalans: ambas tienen de vanguardista la técnica y el juego provocador, pero también tienen de realistas su voluntad de dar cuenta de una época y de unos personajes capaces de representarla.

Por eso, finalmente, y a mi modo de ver, es diferente el trato que Max asigna a sus apócrifos, Campalans y Petreña, del que asigna a Buñuel. A aquellos los ubica en la línea de la Vanguardia que él rechaza, a este en la que al fin viene a afirmar él. Los apócrifos son los antagonistas de su programa ético-estético; Buñuel, con todas sus contradicciones, es su aliado. En el ajuste de cuentas con el arte y la literatura contemporáneas, que alimenta buena parte de la escritura de Max Aub ya desde 1934, el saldo de Campalans y Petreña es netamente crítico, representan la vía que debe ser abandonada. En el balance final de Buñuel, Max encuentra, en cambio, algo de lo que él ha venido buscando ansiosamente: sumar las fuerzas de la Vanguardia a las del Realismo. El saldo, por consiguiente, había de ser positivo. Buñuel personaje se presenta así, para Max, como la superación necesaria de Petreña y de Campalans.

Pero en última instancia, Petreña, Campalans y Buñuel, apócrifos del yo, expresan la dispersión del sujeto clásico, el estallido de su identidad sustancial, inconfundible e indivisamente individual, el de la confianza en su autodeterminación, el de su fundamento en la Razón, y se configuran todos ellos como las figuras de un juego que adquieren su identidad por las posiciones respectivas que ocupan, recortándose unos frente a otros y frente a su autor; un juego que no domina y en el que también se la juega el propio autor. 


\section{NOTAS}

1 Entiendo aquí «inmanente» como opuesto a "trascendente», y en un sentido kantiano: lo inmanente es lo que se produce dentro de los límites de la experiencia posible, en un universo físico, o naturaleza.
2 Para el estudio de la tradición apócrifa europea véase la tesis de doctorado de María Rosell (2011)

\section{BIBLIOGRAFÍA}

Álvarez Barrientos, Joaquín (2009), "Falsificación política, e historia literaria: Mateo Alemán, el padre Isla y Moratín”. En: Álvarez Barrientos, Joaquín; Cornago Bernal, Óscar; Madroñal, Abraham y Menéndez Onrubia, Carmen (eds.), En buena compañía. Estudios en honor de Luciano García Lorenzo, Madrid, CSIC, pp. 821-830.

Althusser, Louis (1965), Pour Marx, Paris, Maspero.

Aub, Max (1966), Manual de literatura española, México, Editorial Pormaca.

Aub, Max (1969), Poesía española contemporánea, México, Ediciones Era.

Aub, Max (1985), Conversaciones con Buñuel, seguidas de 45 entrevistas con familiares, amigos y colaboradores del cineasta aragonés, Prólogo de F. Álvarez, México, Aguilar.

Aub, Max (2001), Cuerpos presentes, Segorbe, Fundación Max Aub.

Carreño, Antonio (1981), La dialéctica de la identidad en la poesía contemporánea. La persona, la máscara (Unamuno, A. Machado, Fernando Pessoa, V. Aleixandre, J. L. Borges, Octavio Paz, Max Aub, Félix Grande), Madrid, Gredos.

Ferrater Mora, José (1965), "Persona". En: Diccionario de Filosofía, Vol. II, Buenos Aires, Sudamericana, 5a ed., pp. 402-405.

Freud, Sigmund (1970), El malestar en la cultura, traducción de Ramón Rey Ardid, Madrid, Alianza Editorial.

Fuentes, Víctor (ed.) (1993), "La otra cara del 27: la novela social española, 1923-1939”, Letras Peninsulares, 6 (1), pp. 9-396.
Habermas, Jürgen (1987), Teoría de la acción comunicativa, Madrid, Taurus.

Hauser, Arnold (1964), Historia social de la literatura y el arte, Madrid, Guadarrama.

Machado, Antonio (1928a), "Una carta de Machado sobre poesía", La Gaceta literaria, 2 (34), p. 1.

Machado, Antonio (1928b), “Diálogo entre Juan de Mairena y Jorge Meneses". En: Poesías Completas, Madrid, Espasa-Calpe, 2ª ed., pp. 261-266.

Mirandola, Pico della (1984), De la dignidad del hombre, edición de Luis Martínez Gómez. Madrid, Editora Nacional.

Nietzsche, Friedrich (1975), Así hablaba Zaratustra, traducción de Andrés Sánchez Pascual, Madrid, Alianza Editorial.

Oleza, Joan (2003), "Jusep Torres Campalans o la emancipación del apócrifo". En: Tomás, Facundo (ed.), La novela de artista, Valencia, Biblioteca Valenciana, pp. 301-330.

Pessoa, Fernando (1984), Libro del desasosiego, traducción de Ángel Crespo, Barcelona, Seix Barral.

Rosell, María (2011), El yo apócrifo: Max Aub ante la mascarada artística de la Modernidad, Tesis Doctoral, Valencia, Universidad de Valencia.

Wellmer, Albrecht (1988), "La dialéctica de la modernidad y postmodernidad". En: Picó, Josep (ed.), Modernidad y postmodernidad, Madrid, Alianza Editorial, pp. 103-140. 